The flu $\mathrm{HQ}$

Leading virologists

plan to thwart

emerging strains of

influenza by creating

a global laboratory

to keep tabs on this

ever-changing virus.

Alison Abbott reports.

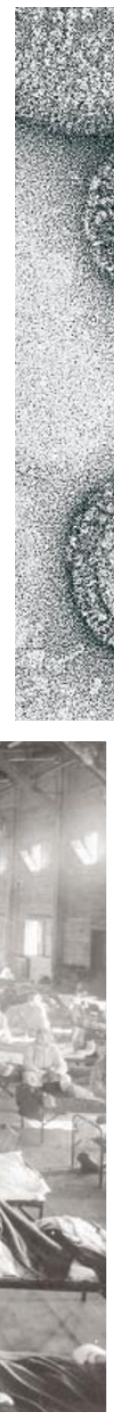

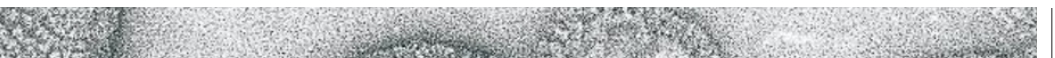

3.
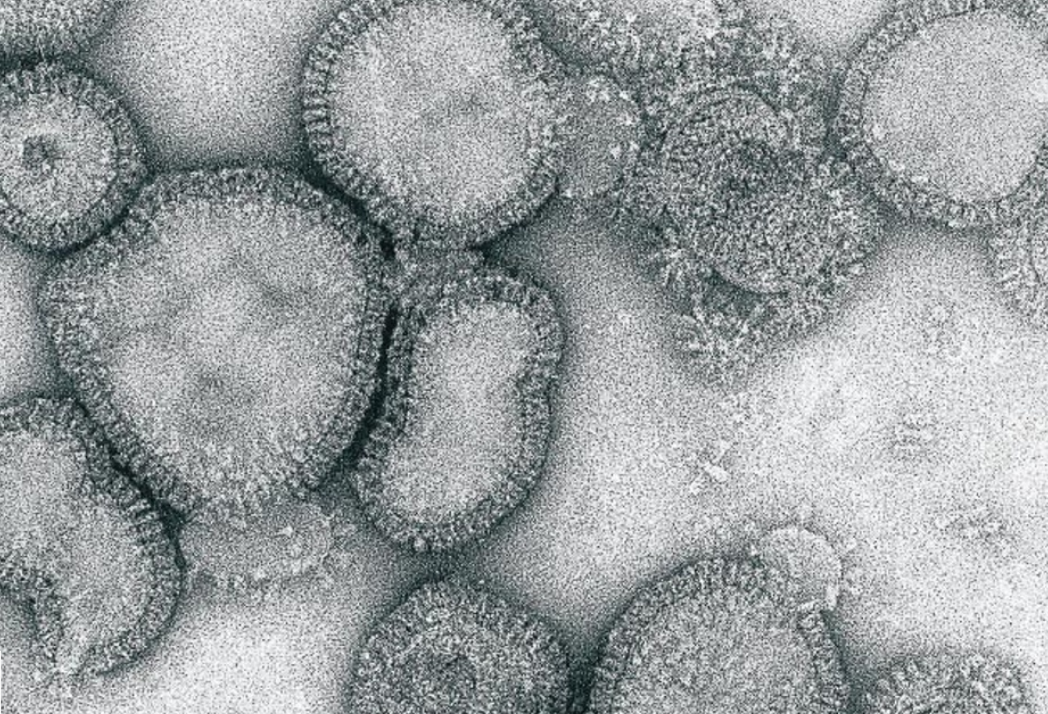

$\mathrm{D}$ uring the Northern Hemisphere's coming winter, tens of thousands of people may die of influenza. It is a sobering figure, but a mere fraction of the half-million killed in 1968, the last time a flu pandemic swept the globe. And compared with the 40 million who perished in the notorious pandemic of 1918, it is a drop in the ocean.

But sooner or later, another strain of flu virus will emerge with the potential to wreak comparable havoc. When it does, minimizing loss of life will depend on rapidly identifying the threat and producing appropriate vaccines. And that, says an influential group of leading flu researchers, means streamlining the existing monitoring system and creating a new global influenza laboratory. "We need to find a better way to predict the inevitable pandemic, and control it," argues virologist Robert Webster of the St Jude Children's Research Hospital in Memphis, Tennessee.

The proposed global laboratory would build on, and partially replace, the current worldwide flu-monitoring system. This was set up in 1948 by the World Health Organization (WHO) to track circulating strains of the virus in both hemispheres. It comprises more than 100 national centres in 83 countries plus four large 'collaborating centres' in London, Melbourne, Tokyo and Atlanta, Georgia.

Flu is an RNA virus with eight genes. Vaccines to combat it must be updated regularly because the virus frequently changes its appearance in an effort to elude its hosts' immune systems. It does this by mixing and matching varieties of two of its genes. One encodes the protein haemagglutinin, which helps the virus enter host cells; the other generates the enzyme neuraminidase, which allows the virus to burst out of host cells once it has replicated.

\section{Taking the strain}

At present, the national centres collect and screen samples from about 175,000 of the billion or so cases of flu that occur worldwide each year. They classify the viruses into two major subtypes, A and B. Because A is a more variable subtype than $B$, they also document its haemagglutinin and neuraminidase proteins. Most of the flu viruses circulating this year, for instance, are $\mathrm{A}(\mathrm{H} 1 \mathrm{~N} 1), \mathrm{A}(\mathrm{H} 3 \mathrm{~N} 2)$ or B.
The national centres send a representative fraction of the more common strains to one of the collaborating centres for detailed analysis, often including sequencing of the haemagglutinin and neuraminidase genes. All unusual strains are also sent for further analysis. In addition, the national centres deposit epidemiological information into a WHO database set up in 1997 and recently made available online as FluNet, which collates data on disease incidence and circulating strains.

In February and September, scientists from the four collaborating centres meet to decide the composition of the next vaccine. Manufacturers have about six months to prepare the 100 million or more shots that are delivered in each hemisphere's flu season.

Most experts agree that the system works well - but not well enough to be sure that it can react to an emerging pandemic with the necessary speed. Taking advantage of highthroughput gene-sequencing technologies, leading flu specialists - including representatives of the four WHO collaborating centres - want to establish a central global facility to type and sequence samples submitted by national centres. "This is the lab of the future: 
| highly automated, very centralized and very efficient," says Alan Hay, director of the WHO Collaborating Centre for Reference and Research on Influenza at the National Institute for Medical Research in London.

\section{Rapid response unit}

At present, the four collaborating centres between them produce sequence information on only 4,000 or so samples each year. Under the global laboratory proposal, outlined in September in Science (293, 1729; 2001), this would be increased by at least an order of magnitude. Results would be made available to those submitting samples within days - currently, this can take several weeks. The national centres would increase their gathering of epidemiological data, which would be submitted to the central lab.

With the swifter flow of greater volumes of data, up to a month could be gained between the identification of new circulating viruses and the start of vaccine development, say the plan's proponents. But Klaus Stöhr, an official responsible for flu at the WHO's Geneva headquarters, notes that the biggest delay - of between six and eight months is in vaccine manufacture. "A month or two will not make up this lag," he says.

The global lab should bring other gains, however. Good information about mutations in the neuraminidase gene, for instance, would help keep track of the emergence of resistance to drugs that work by inhibiting the enzyme, such as Relenza (zanamivir).

Perhaps most significantly, the global lab should accelerate understanding of the virus's biology — which would help explain why some strains of flu are more dangerous than others. This knowledge could allow virologists to predict whether newly emerging strains have the potential to cause a pandemic.

Even in the absence of a pandemic strain, scientists need to get a better handle on why flu is more virulent one year than the next, says Michèle Aymard, head of the National Reference Centre for Influenza in Lyon: "Flu is so common and we know so little about it." In the winter of 1992-93, for instance, Aymard observed unusually high rates of hospitalization in France, as well as outbreaks in elderly

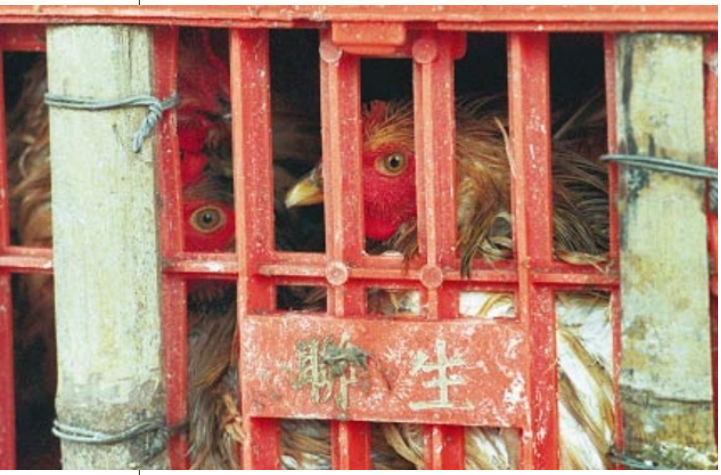

Flu from animals, such as poultry, can infect people, as happened in Hong Kong in 1997. people who had been vaccinated, without being able to provide a scientific explanation.

Nancy Cox, head of the WHO collaborating centre at the US Centers for Disease Control and Prevention in Atlanta, is convinced that widespread sequencing of genes other than those for haemagglutinin and neuraminidase will reveal important virulence factors. "We need to find other molecular signals for changes in virulence for which we do not have good markers," she says.

One example could be the NS1 gene, which Peter Palese, a flu virologist at the Mount Sinai School of Medicine in New York, suggests could promote virulence because the protein it encodes neutralizes the effects of interferon, an antiviral protein made by the immune system. He suspects that mutations in this gene may explain why the strain of virus that caused the 1918 pandemic was so extraordinarily virulent. "A protein that targets the host's defence response could provide a logical explanation," says Palese. The chance to compare NS1 mutations with epidemiological data would put the theory that the gene is a key virulence factor to the test.

Haemagglutinin itself is also known to be a powerful virulence factor. The major twentieth-century pandemics - caused by an $\mathrm{H} 1 \mathrm{~N} 1$ virus in 1918, H2N2 in 1957 and H3N2 in 1968 - were each associated with a subtype of the haemagglutinin gene to which people had not previously been exposed.

\section{Exchange rates}

It is widely believed that these pandemic viruses arose because of gene reassortment in which a virus from an animal - birds, pigs and horses all harbour flu - co-infected a host cell with a human virus and an exchange of genes occurred. "Observing the frequency of reassortment of genes in strains analysed by the global laboratory will be important to see the processes involved in generating pandemics," says Cox.

The global laboratory would also monitor strains of flu in animals. The importance of this was underlined in late 1997, when an H5N1 strain of flu crossed over from poultry to people in Hong Kong and caused several deaths. In the event, it was not the start of a pandemic — but the threat of a devastating virus suddenly emerging from birds or other animals remains. "The identification of novel influenza subtypes in animals may turn out to be directly predictive of a human pandemic and thus allow vaccines to be manufactured in advance of a major outbreak," says Jeffrey Taubenberger, a virologist at the US Armed Forces Institute of Pathology in Washington.

Although the global laboratory plan has strong support among independent flu virologists and at the existing collaborating centres, some scientists at the national centres remain unconvinced. "There are better and cheaper ways to improve the flu surveillance system," argues Reinhard Kurth, head

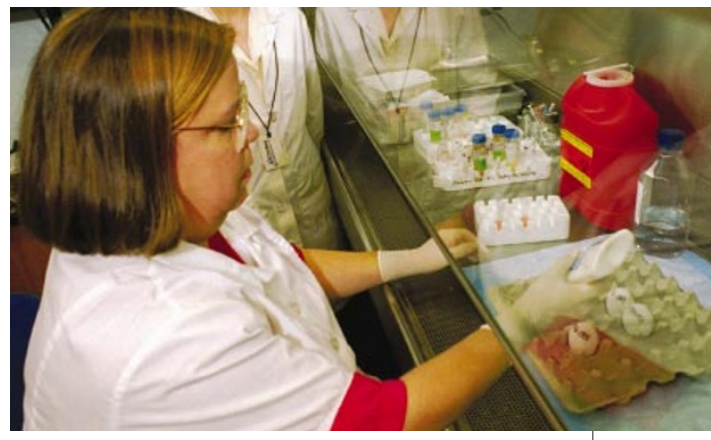

Nancy Cox: wants more genetic information.

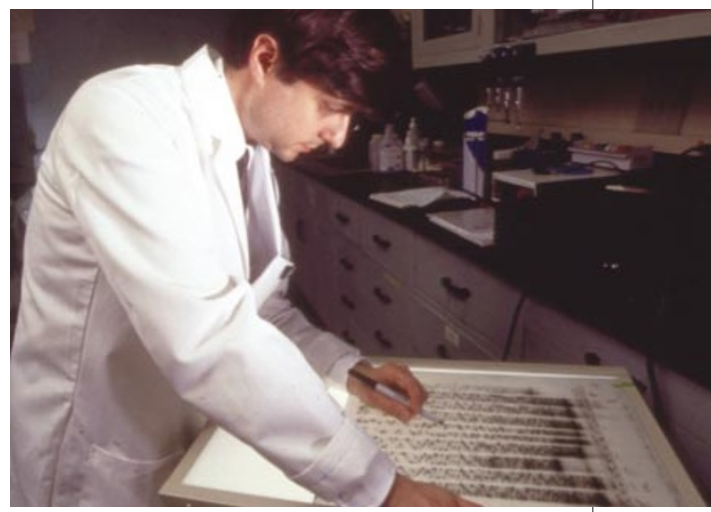

Pandemics could be thwarted by spotting new flu strains in animals, says Jeffrey Taubenberger.

of the Robert Koch Institute in Berlin, which is home to one of Germany's national centres. He points to the WHO's current efforts to improve communication between national centres, through initiatives such as extending FluNet and establishing a new helpdesk in Geneva to answer queries from the centres.

Kurth also worries that scientists at the national centres will lose their enthusiasm if their jobs are reduced to posting samples for analysis elsewhere. But Hay argues that this will not happen: "Really it will liberate them from the routine - the truly scientific work will still need to be done."

Moving the plan forward will require money - around US $\$ 50$ million for the first five years, to build, equip and run the global laboratory. Although the plan envisages that $\mathrm{WHO}$ would continue its coordinating role, the agency does not have the necessary money to fund the lab. So the plan's proponents are looking to philanthropic organizations such as the Bill \& Melinda Gates Foundation.

Scott Layne, a physicist-turned-physician at the University of California, Los Angeles, who is one of the driving forces behind the initiative, is confident that it "could save untold numbers of lives". If so, the global laboratory concept might be applied to other diseases. And, in the current climate, it may also be examined in the context of monitoring bioterrorist incidents.

Alison Abbott is Nature's senior European correspondent. WHO flu factsheet www.who.int/inf-fs/en/fact211.html FluNet oms.b3e.jussieu.fr/flunet 